\title{
MANITOBA HYDRO ACCOMMODATES OSPREY ACTIVITY
}

DAVID C. VANDERBURGH, 125 Dunfield Ave., Dauphin, Manitoba R7N OP1

Because of the Osprey's tendency to frequent power lines located near bodies of water, problems are bound to arise. In an attempt to maintain the security of lines in the Waterhen and Mossey River areas, and ensure the safety and continued presence of the birds, Manitoba Hydro Operating,

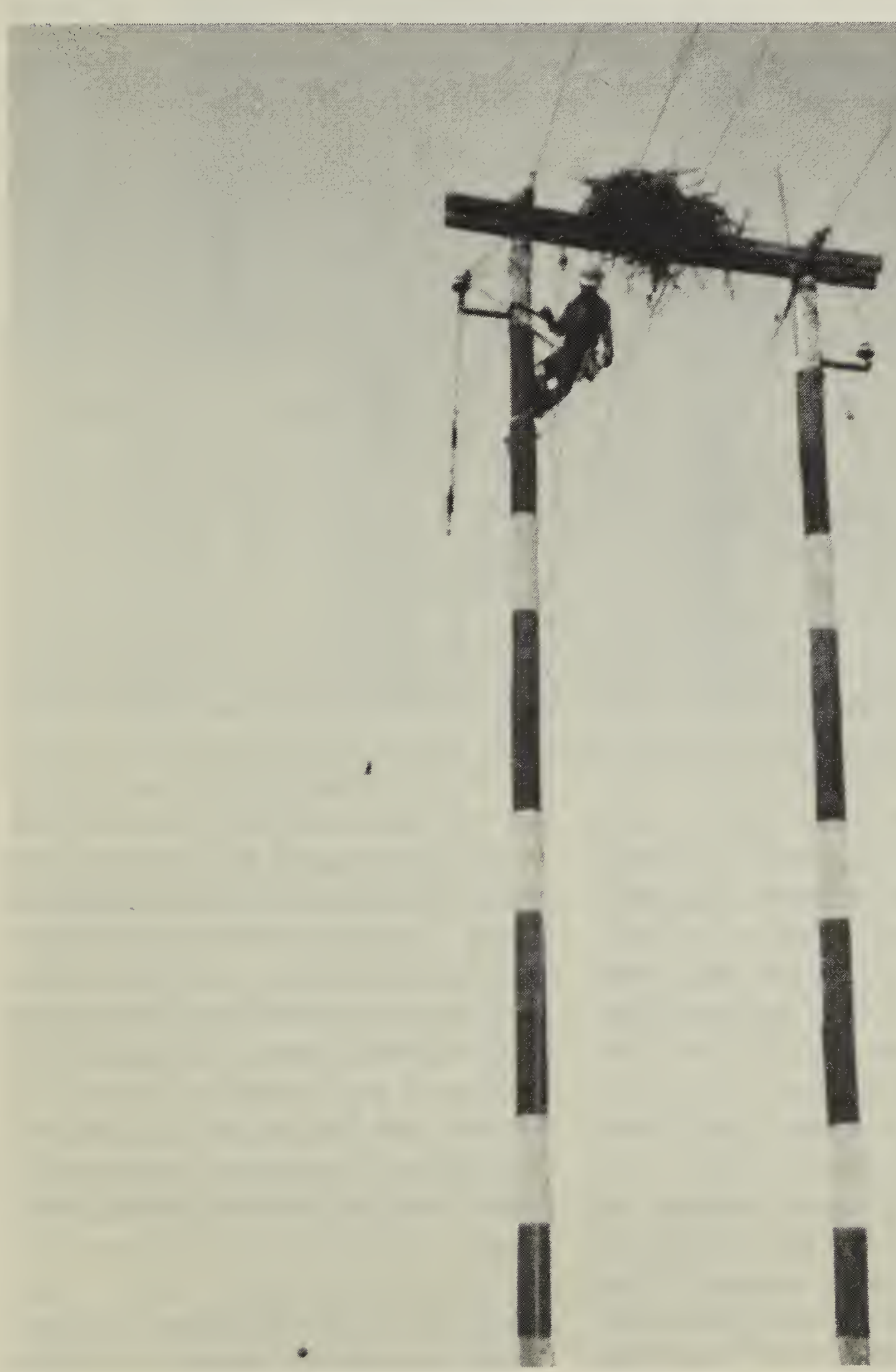




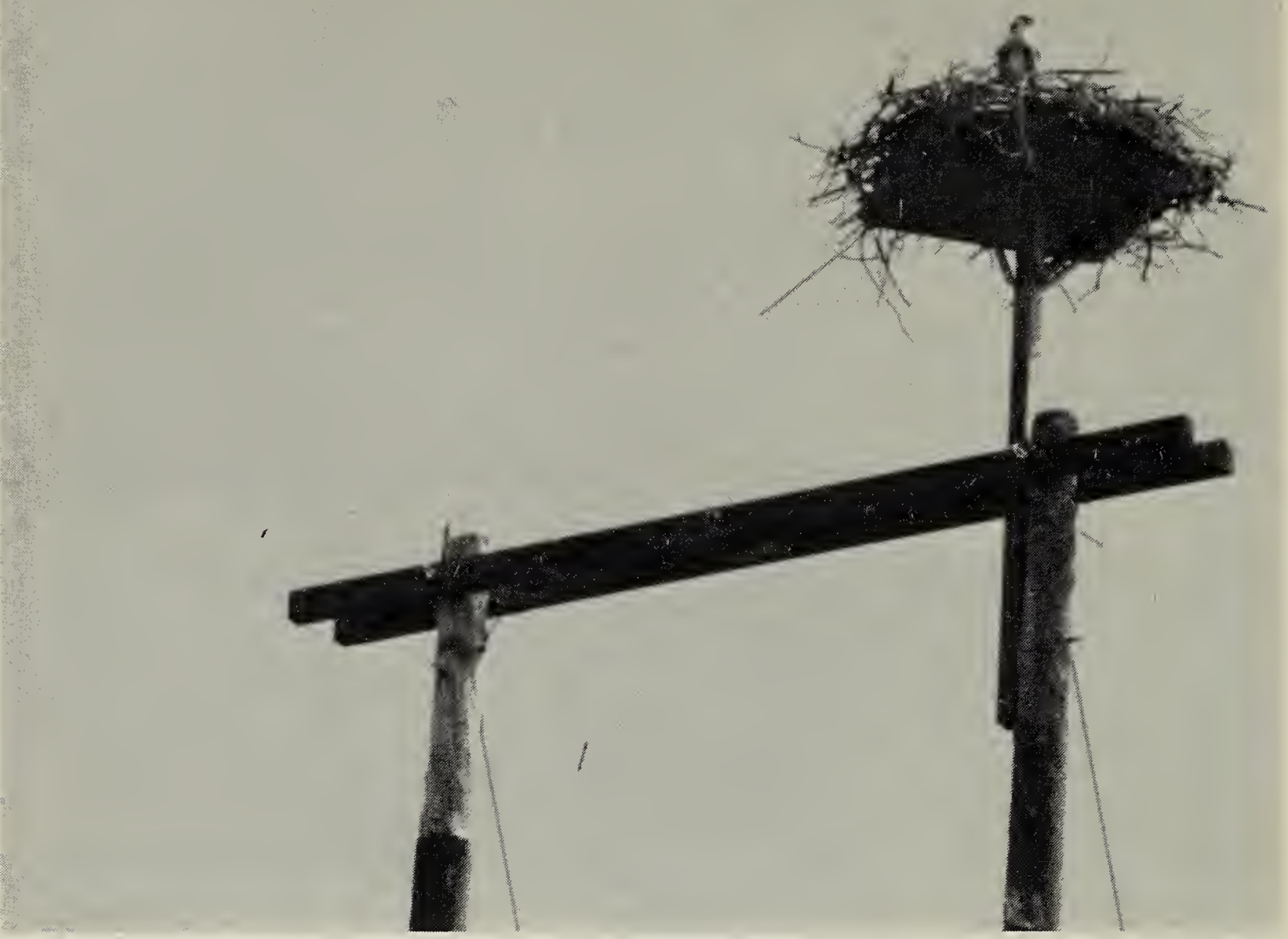

New location of Osprey nest on structure above live power lines.

D. Vanderburgh

Engineering and Construction staff have developed some interesting approaches to this problem.

The Osprey habit of carrying long, wet sticks to the top of hydro structures has caused lines to trip out and even set fire to the tops of the structures. The potential for injury to the birds themselves is, of course, very high. Ste. Rose du Lac operating staff first addressed this problem with an innovative solution in 1988. An Osprey nest with three eggs had been built directly over an energized conductor on the 25,000-volt line crossing the Waterhen River between Waterhen Lake and Lake Manitoba at SW28-32-15W. The nest was in imminent danger of shorting out the line and probably injuring the adult birds as well. The easy solution would have been to simply dislodge the nest from the structure. However, Barry Paradis and Len Kendzierksi of the Ste. Rose operating staff decided to attempt to save the nest and its contents.

They contrived an artificial nesting platform from plywood and a cross arm, and, with both men up in the structure, were able to actually transfer the nest and eggs to this platform. They raised the platform well above the conductors and bolted it in place. The adult birds accepted their new quarters and went on to successfully rear three young that year. This success was monitored and confirmed by Cameron Peterson of the Natural Resources Department. The platform has been in place since 1988 and has been occupied every year.

In July 1992, because of power line improvements being made in the Waterhen area, Hydro decided to 


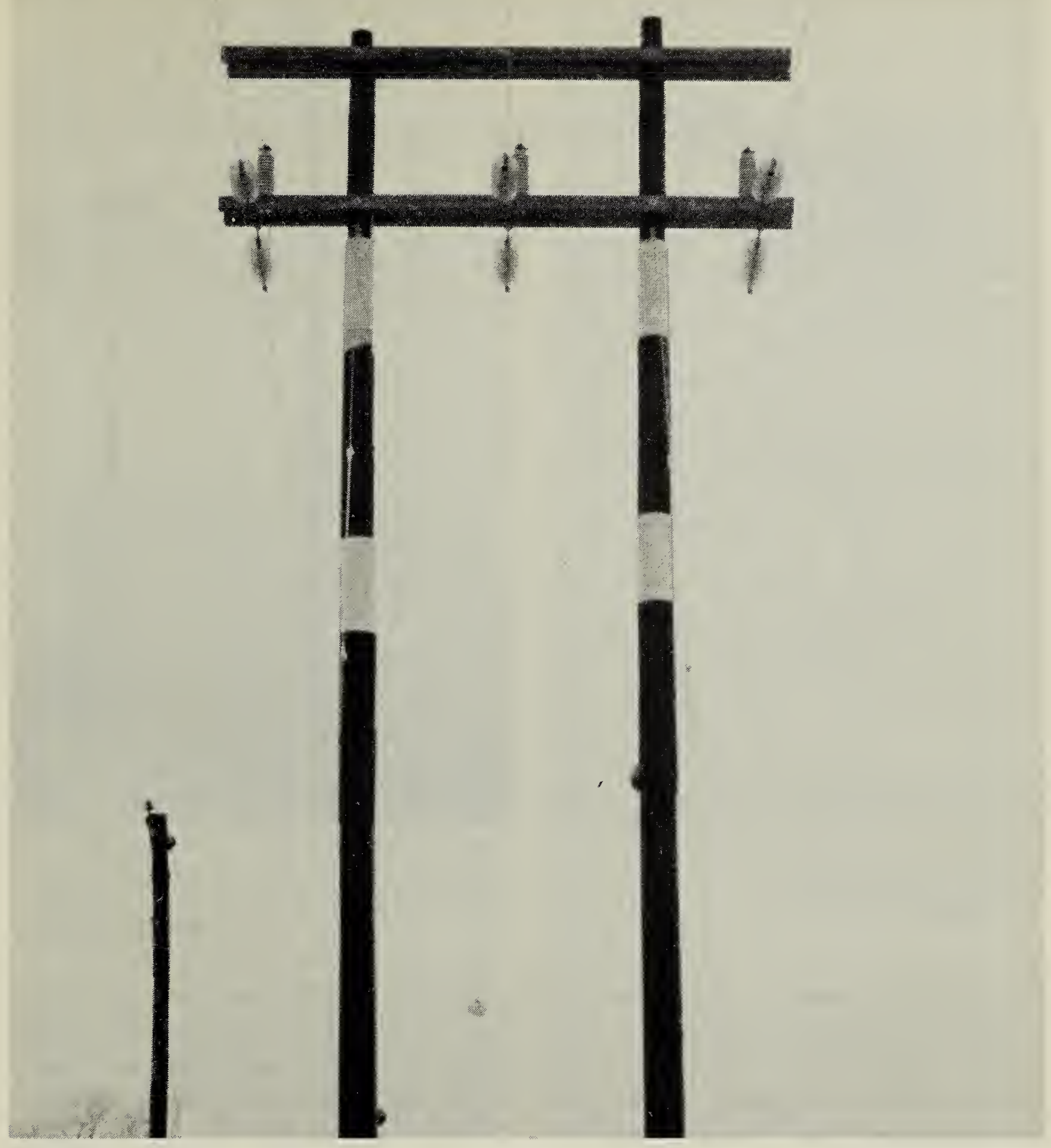

Osprey-friendly "empty" timbers provide safe nesting area well above 66,000 volt transmission lines.

D. Vanderburgh

remove this river crossing circuit. I arranged for this structure plus two adjacent structures to be left in place specifically for Osprey activity. Marvin Roos, Western Region line crew foreman, and his crew carefully removed the conductors from the crossing structures without unduly disturbing the nesting birds. Marvin also photographed the nest with three eggs from their aerial bucket truck. I later observed and photographed young birds in the nest. With the removal of all overhead conductors from the crossing com- pleted, Hydro activity has now ceased and the three structures are left "for the birds" to hopefully complete this and many future successful seasons.

I also redesigned two other Osprey-friendly crossing structures:

1) In the summer of 1991, two new 66,000 -volt structures spanning the Mossey River between Lake Dauphin and Lake Winnipegosis at SE18-30-18W were completed by Marvin Roos and his line crew. The 


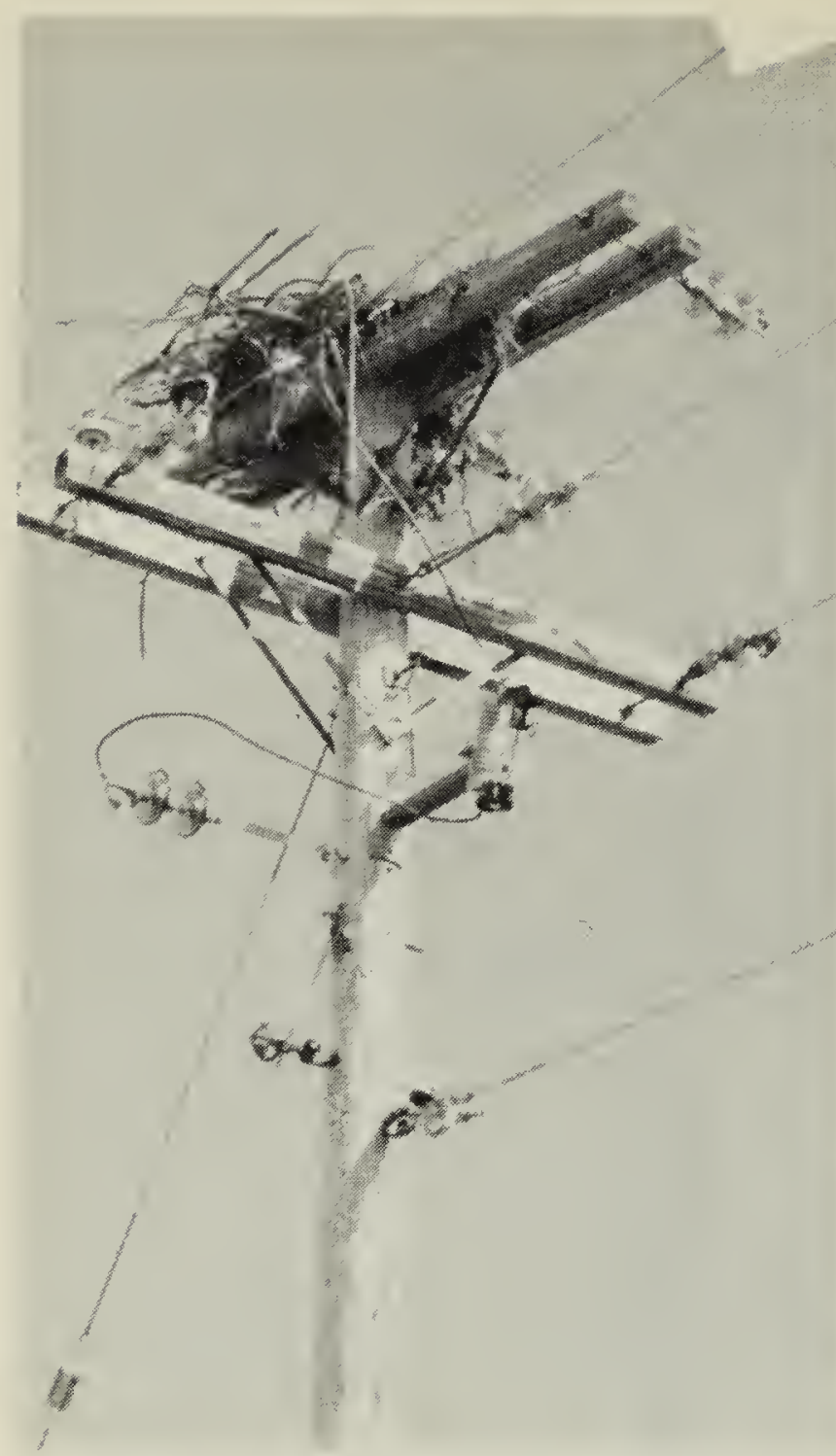

Partially constructed nest on unsuitable corner pole.

D. Vanderburgh

poles. This provides a safe and secure area for Osprey activity.

2) The second crossing, located on the Waterhen River between Waterhen Lake and Lake Manitoba SW8$34-15 \mathrm{~W}$ was similarly designed and built several years ago on a 25,000 volt power line.

This was in direct response to several power outages due to Osprey activity during a one-week period in the spring. At the time, an active nest was situated a few spans west of this crossing. Unfortunately, it blew down in high winds shortly after the Osprey-friendly structures were completed. The Osprey nest was not re-established but Bald Eagles now have an active nest at this same location.

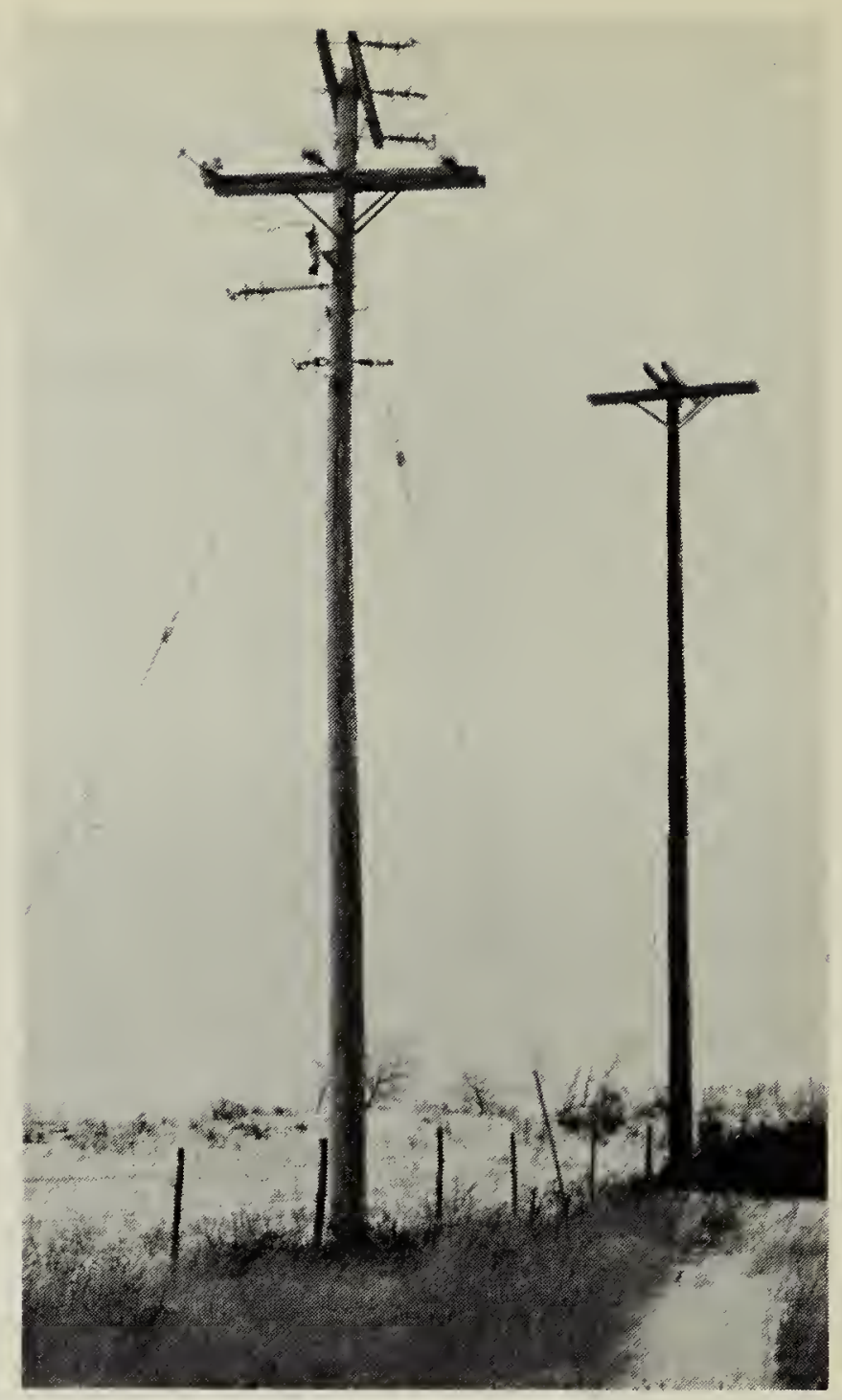

Special "nesting pole" installed to attract Ospreys away from 25,000-volt corner pole.

D. Vanderburgh

Another Osprey event occurred on the west shore of Lake Manitoba SW6-32-15W in the spring of 1991. A pair attempted to build a nest on a 25,000-volt power line corner pole. Because of the unsuitability of this particular pole, Murray Makinson, Ste. Rose district operator, and I conferred and agreed that the partially constructed nest must be removed. This was done twice as the birds immediately tried to re-establish. This same scenario was repeated in the spring of 1992 as another attempt to nest was made at that time. In all three cases, no eggs were involved. Following this last attempt, I arranged for a special pole with a nesting platform to be installed beside this unsuitable corner pole, hoping the birds would attempt to nest there the following spring. 